\title{
Hexokinase Measurement
}

National Cancer Institute

\section{Source}

National Cancer Institute. Hexokinase Measurement. NCI Thesaurus. Code C96668.

The determination of the amount of hexokinase present in a sample. 